\title{
Osmanlı İmparatorluğu'nda 1730 İsyanı Üzerine Yeni Bir Eser: Vâkıa Takrîri Bin Yüz Kırk Üç'de Terkîb Olunmuşdur
}

\author{
A New Source on the 1730 Rebellion in Ottoman History: \\ An Account of the Rebellion that Happened in \\ Constantinople in Hegira 1143
}

\section{Selim KARAHASANOĞLU*}

$\ddot{o} z$

Bu makalede, Bibliothéque Nationale de France, Manuscrits orientaux arasında, SUPPL. TURC serisi, 923 numara içerisinde Vâkıa Takrîri Bin Yüz Kırk Üç'de Terkîb Olunmuşdur isimli, modern literatürde Patrona İsyanı olarak bilinen 1730 isyanına dair, bugüne kadar literatürde işlenmemiş bir eseri tanttiyoruz. Ayrıca, eserin içeriğine dair de bilgi vererek 1730 isyanına dair bilgimize yeni neler kattığını sorguluyoruz.

Anahtar Kelimeler: 1730 İsyanı, Patrona Halil, Osmanlı Tarih yazımı.

\section{Abstract}

This article introduces a previously untapped manuscript from Bibliothéque Nationale de France, (Manuscrits orientaux, SUPPL. TURC 923): Vâkıa Takrîri Bin Yüz Kırk Ü̧̧'de Terkîb Olunmuşdur/An Account of the Rebellion that Happened in Constantinople in Hegira 1143. This manuscript details the 1730 rebellion in Ottoman history which came to be known as Patrona Rebellion in modern Ottoman historiography. Beyond introducing the manuscript, this article also elucidates the ways in which the content of the manuscript contributes to our existing knowledge on the rebellion.

Keywords: 1730 Rebellion, Patrona Halil, Ottoman Historiography. 
Vâkıa Takrîri Bin Yüz Kırk Üç'de Terkîb Olunmuşdur ${ }^{1}$ başlıklı eser, Fransa Milli Kütüphanesi'nde, Manuscrits orientaux arasında, SUPPL. TURC serisi, 923 numara içerisinde bulunmaktadır. Bu eser, toplam 96 varak olup ilk 30 varağı bahsini ettiğimiz eser olan Vâkıa Takrîri'dir. Ardından 43 varaklık bir kısımda eserin dönemde gerçekleştirilmiş el yazısı Fransızca çevirisi söz konusudur. Bunu takiben, 9 varaklık, bahsini ettiğimiz eserle ilgisi olmayan bazı Osmanlıca mektuplar yer alır ve yine 14 varakta mektupların Fransızca çevirileri mevcuttur. Yani eserin şimdilik doğrudan bizi ilgilendiren kısmı, ilk 30 varaklık kısmıdır.

Vâkıa Takrîri, modern Osmanlı tarihyazımında Patrona İsyanı ya da Patrona Halil İsyanı olarak adlandırılagelen 1730 (Hicri 1143) isyanı üzerine kaleme alınmış bir kaynak olup ilk kez bu makalede tanıtılmaktadır. ${ }^{2}$ Eserden Osmanlı tarihi literatüründe tek bahis, isminin anılması ile sınırlıdır. M. Münir Aktepe, Patrona İsyanı (1730) ${ }^{3}$ isimli çalışmasının kaynakçasında eserin adını zikretmekte ${ }^{4}$, fakat çalışmasında eseri kullanmamaktadır. ${ }^{5} 1730$ isyanı, Patrona Halil'in görünür liderliğinde bir grubun isyanı olup Ayasofya Vaizi İspirizade Ahmed Efendi, İstanbul'dan mazul kadı Zülali Hasan Efendi ve daha başka şahıslar tarafından organize edilmiş ve Sadrazam Nevşehirli Damad İbrahim Paşa'nın iki damadı ile beraber idamına ve Sultan III. Ahmed'in tahttan indirilmesine neden olmuştur. ${ }^{6}$

1730 y1lı ve öncesi olayları dönemin vakanüvisi Küçük Çelebi-zâde İsmail Asım Efendi'nin kroniğinde kaydedilmemiştir. ${ }^{7}$ Osmanlı Arşivi'nde de isyan; belge, dosya ve defter tasnifleri içerisinde adeta silik gibidir. $\mathrm{Bu}$ durumun İstanbul mahkemelerine ait 27 mahkemenin şer'iyye sicillerinde de

*Dr. Pamukkale Üniversitesi Fen-Edebiyat Fakültesi, Tarih Bölümü

${ }^{1}$ Bibliothéque Nationale de France, SUPPL. TURC 923. Eserin tamamının transkripsiyonu tarafımızdan gerçekleştirilmiş olup yakın zamanda yayımlanacaktır. Bundan sonra, makale boyunca, eserden Vâkıa Takrîri diye bahsedilecektir.

${ }^{2} 1730$ isyanına değinen çalışmalar içerisinde, Vâkıa Takrîri ilk kez şurada kullanıldı: Selim Karahasanoğlu, A Tulip Age Legend: Consumer Behavior and Material Culture in the Ottoman Empire (1718-1730), Basılmamış Doktora Tezi, (State University of New York at Binghamton), Binghamton, New York, 2009.

${ }^{3}$ M. Münir Aktepe, Patrona İsyanı (173), İstanbul: Edebiyat Fakültesi Basımevi, 1958.

${ }^{4}$ Aktepe, eserin başlığındaki "terkîb” kelimesini, sehven olacak, "tahrîr" olarak okumuştur.

${ }^{5}$ Muhtemelen, Aktepe, kitabını hazırlarken 1730 isyanına dair Fransa Milli Kütüphane'sinde bahsi geçen eserin varlığını tespit etmiş fakat, bilemeyeceğimiz bir sebeple, bir kopyasını edinememiştir. Aktepe'nin Patrona İsyanı'nın kaynakçasında Vâkıa Takrîri'ne yer vermesi, fakat çalışmasının içerisinde metne hiç referans vermeyişi Erhan Afyoncu'nun da dikkatinden kaçmamıștır. Bkz. Erhan Afyoncu, Tanzimat Öncesi Osmanlı Araștırma Rehberi, İstanbul: Yeditepe Yayınevi, 2007, s. 90.

${ }^{6}$ İsyan üzerine ayrıntılı bir analiz için bkz. Karahasanoğlu, A Tulip Age Legend, s. 169-221.

${ }^{7}$ Bkz. Küçük Çelebi-zâde İsmail Asım Efendi, Tarih-i Asım, İstanbul, 1865. 
aynen tekrarlandığını söylemek mümkündür. Böylece, 1730 isyanı çevresindeki İstanbul'u ve Osmanlı tarihini aydınlatmanın güçlügüü ortadadır.

18. yüzyıl başında münhasıran bu isyan üzerine kaleme alınmış ve 20 . yüzyılda ise yayımlanmış literatürde iki eser mevcuttur:

1. 1730 Patrona Ihtilâli Hakkında Bir Eser: Abdi Tarihi, Yayına Hazırlayan: Faik Reşit Unat, Ankara: Türk Tarih Kurumu Basımevi, 1943.

2. Destârî Sâlih Tarihi: Patrona Halil Ayaklanması hakkında bir kaynak, Yayına Hazırlayan: Bekir Sitkı Baykal, Ankara: Türk Tarih Kurumu Basımevi, 1962.

$\mathrm{Bu}$ iki eser, isyan üzerine literatürdeki temel eserlerdir. Biz ise bu makalede, isyan üzerine müstakil olarak kaleme alınmış, bu kez İstanbul kütüphanelerinde mevcut olmayan üçüncü bir temel çalışmaya dikkat çekiyoruz. Eser, dönemin çağdaş bir kaynağı olup isyanı bütün yönleri ile tasvir etmektedir. Açıktır ki; Osmanlı tarihinde, bu tür eser kıtlığının söz konusu olduğu hadiselerin aydınlatılmasında, yeni bulunan ek kaynakların bir önceki yazarın söylediklerini teyit edici bilgiler vermesi kritik önemdedir. Vâkıa Takrîri, bu tür bir muğlak dönemin aydınlatılmasında teyit mahiyetinde bilgiler içermesinin yanısıra ilave bilgiler içermesi yönüyle de önemlidir. Bunun ötesinde, isyana dair üçüncü bir tarihsel öykünün ortaya çıkarılması başlı başına değerlidir.

1730 isyanını ele alan çağdaş kaynaklar içerisinde, modern literatürde, en meşhur olanı Abdi Tarihi'dir. Zira, Abdi hem isyan üzerine derli toplu bilgiler sunar, hem de dili oldukça sadedir. Bunun yanında, Destari Tarihi'nin sahip olduğu ağdalı anlatım onun, Abdi kadar geniş kullanım sahası bulmasını engellemiştir.

Osmanlı tarihçiliğinde temel kaynakların neşri konusunda mevcut düzeyin yetersizliği ortadadır. Günlükler, masraf defterleri, paşa muhallefatları gibi kaynakların neşrinin sağlayacağı analitik kolaylıkların açıklığı bir yana temel kroniklerin, ana tarih eserlerinin dahi tenkitli metinlerinin olmayışının yol açtığı noksanlık araştırmacıların malumudur. $\mathrm{Bu}$ açıdan, 1730 isyanı gibi temel bir Osmanlı tarihi hadisesini mercek altına alan bu eserin ehemmiyeti ortadadır. Bekir Sttk1 Baykal, Destari Tarihi neşrine yazdığı önsözde Abdi Tarihi'nin isyana dışarıdan bir bakış olması münasebetiyle isyancıların hallerini ayrıntısı ile izah ettiğini Destari'nin ise saray içerisinden olmasının ona isyanın içeriden tarifini gerçekleştirme imkanı verdiğini söyler. Vâkıa Takrîri için ise bu düzeyde bir fikir yürütmek şimdilik zor gözükmektedir. Zira, yazarının kimliği konusunda bilgimiz yoktur. Ancak, eserdeki ifadeleri onun isyanın çok yakın bir gözlemcisi 
olduğunu göstermektedir. Eserin önemi için de bu yeter derecede önemlidir. Bu noktayı biraz belirginleştirebilmek için metinden aşağıdaki kısma bir göz atalım:

“... küşte-i selasenin saraylarında defn ve iddihar eyledikleri mal-1 mahzûnu ... karîb mahremlerinden istihbar olundukda vezir-i mahrûmun ... miftah namına olan oğlan, efendinin malı nerde medfûn olduğunu ancak ben bilirum deyu ... sarayında ... ve ... İstambul sarayında meskûk findık ve zincirlu altın ve Kethüda'nın kezalik harem kethüdası namına Mustafa Ağa mezkûr oğlan gibi itiraf idüb üç bin kiselik altun olmak üzere ... sandukları bâb-1 hümayunda müşahede eyledik..."”

Yazarın "müşahede eyledik" ifadesi olayın aktif katılımcısı olduğu izlenimini vermektedir. Bu satırlar, Damad İbrahim Paşa ve iki damadının öldürülmesini takiben mallarının müsaderesinde birinci derecede gözlemcinin izlenimleridir. Metinden aktardığımız bu kısa pasajda dahi hemen dikkati çekeceği üzere bu eser, isyanın tarafları üzerine oldukça sivri ifadelere yer vermektedir. Bu İbrahim Paşa ve ekibi için de doğrudur, isyanın organizasyonunu üstlenen ekip için de. Yukarıdaki metinde geçen "vezir-i mahrûm" ifadesi buna bir örnektir. Örnekleri biraz çoğaltalım: Yazar, isyanın organizatörlerinden Ayasofya Vaizi İspiri-zâde Ahmed Efendi için "şeyh-i mesfûr", "şeyh-i bî perva" (vr. 9b) ifadelerini kullanır. Yine İbrahim Paşa ve ekibinin katllerinin ardından müsadere ile gelen altınlarının bolluğu karşısında "mechulu'n-neseb" (vr. 12a) bir insanda bu kadar zenginliğin anlamını sorgulayacaktır ve "Karun dahi bu kadar medfun altuna malik olmayub" (vr. 12a) bunlara göre ancak bir dilenci idi diyerek durumu daha da büyütecektir.

Vâkıa Takrîri, isyan üzerine diğer eserlerdeki gibi hicri 1143 senesinin Rebiülevvel ayının onbeşinci günü ile başlar; isyancıların kellelerinin alınması ile son hikaye son bulur. Eser, işte bu arada, yani isyanın patlak vermesi ile isyanciların kellelerinin alınması sonucu durulan ortamdaki ilişkiler yumağını çözmede önemli bilgiler sunar. 1730 isyanı, eğer bir kazananlar ile kaybedenlerin mücadelesi ise bu çekişmenin taraflarını belirlemek kritik önemdedir. İşte Vâkıa Takrîri, öne çıkardığı bazı isimlerle bu tarafların aydınlatılmasında dolayısıyla III. Ahmed'in hal'i ve I. Mahmud'un saltanatının başlangıcı dönemindeki mücadelenin doğasını kavramamıza yardım eder. Vâkıa Takrîri'nde bir isimler karmaşası söz konusu değildir. Taraflar çok net ve basit anlatılır. Eserin hemen başında Patrona Halil'in yanında "birbirlerine muvafik" iki isme yer verir: Musli ve Kara Ali (vr. 2a). İsyanın elebaşları olarak (gerçekte görünürde de olsa) bu

${ }^{8}$ Vâkıa Takrîri, vr. 11a-11b. 
üç ismi sayarken isyanın bastırılmasında da Pehlivan ve Koca Reis'i öne çıkarır. Şüphesiz, Muhsinzade Abdullah Paşa ve Canım Hoca Mehmed Paşa'nın isyanın bastırılmasındaki fonksiyonunu vurgular. Vâkıa Takrîri'nin ayrıntısıyla yer verdiği isyan dönemi figürlerinden biri de Niğdeli Ali Ağa'dır. Burada, Damad İbrahim Paşa döneminde, 1726 yılında, görevinden azledilip Girit'e sürgüne yollanan Ali Ağa'nın isyanda nasıl bir intikam hırs1 ile hareket ettiğini görürüz ve isyan sonrası vezir kethüdalığı gibi önemli bir görevle taltif edildiğine şahit oluruz. Bu ve benzeri ilişkilerin çözümü, 1730 isyanını hazırlayan ve de tetikleyen iktidar mücadelelerini anlamanın kapisinı aralar.

Vâkıa Takrîri'nin denk geldiği tarihsel kesit kritik bir dönemdir. Şöyle ki; 1730 yılı, modern Osmanlı tarihyazımında "Lale Devri'nin” bitişi olarak zikredilmiş; Türkiye'de "batılılaşma"nın başlangıcı olarak ele alınmış ve isyan da tarihsel kontekstinden uzak, Patrona Halil'in şahsını kahraman yahut serseri ilan eden bir ideolojik malzeme haline gelmiştir. ${ }^{9} \mathrm{Bu}$ da doğal olarak isyanı tarihsel bağlamından koparıp, gündelik siyasi tartışmaların bir malzemesi haline getirmiş, Osmanlı devletinin ve toplumunun şahit olduğu önceki ve sonraki isyanlar bağlamında siyasi, ekonomik ve sosyal tabanlı gerekçelerinin ortaya koyulması çabası gösterilmemiştir. Bu tarz bir karşılaştırmalı Osmanlı isyanları çalışmasının temel malzemesi, dönemin yazarlarının kaleme aldıkları, burada tanıttığımız tarzdaki müstakil eserlerdir. Bu eserlerin, olayları tasvir tarzlarının ve yazarlarının konumlarını belirleyişlerinin isyanın taraflarının ortaya konulmasında ve dolayısıyla gerçek çekişme/çatışma noktalarının belirlenmesinde büyük önemi vardır. Zira tarih yazarlarının belli gruplara yakınlıkları isyanları tariflerinde kendi gruplarının görüşünün ortaya çıkarılmasını mümkün kılmaktadır. Bu türlü çıkarımlar ise ancak isyanlara dair mümkün olabilen en fazla sayıda eserin mukayeseli değerlendirilmesi ile mümkündür. Dönemin farklı tarih kaynaklarının bir arada değerlendirilmesinin taban tabana zıt görüşleri nasıl ortaya koyduğunu; esasen tarihi gerçeklik ile tarihyazımının birbiri içerisine nasıl geçtiğini göstermektir. 1730 isyanı ve isyanı önceleyen Osmanlı tarihinin on iki yıllık "kısa" dönemi, Osmanlı tarihçiliğinin en fazla saptırılmış/popülerleştirilmiş dönemidir. $\mathrm{Bu}$ resim içerisinde de 1730 isyanının elebaşı Şaki Patrona/Patrona Halil önemli bir aktör olarak kullanılmıştır. Vâkıa Takrîri'nin, bu önemli tarihsel kesite nitelikli bir katkı sağladığı düşüncesindeyiz.

\footnotetext{
${ }^{9}$ Konunun tarih yazınsal boyutu için bkz. Selim Karahasanoğlu, "Osmanlı Tarihyazımında 'Lale Devri': Eleştirel Bir Değerlendirme”, Tarih ve Toplum: Yeni Yaklaşımlar, 7, 2008, s.129-144.
} 


\section{Kaynakça}

\section{Birincil Kaynaklar}

Vâkıa Takrîri Bin Yüz Kırk Üç'de Terkîb Olunmuşdur, Bibliothéque Nationale de France, Manuscrits orientaux, SUPPL. TURC 923.

Küçük Çelebi-zâde İsmail Asım Efendi, Tarih-i Asım, İstanbul, 1865.

Íkincil Kaynaklar

Afyoncu, Erhan, Tanzimat Öncesi Osmanlı Araştırma Rehberi, İstanbul: Yeditepe Yayınevi, 2007.

Aktepe, M. Münir, Patrona Ísyanı (1730), İstanbul: Edebiyat Fakültesi Basımevi, 1958.

Karahasanoğlu, Selim, A Tulip Age Legend: Consumer Behavior and Material Culture in the Ottoman Empire (1718-1730), Basılmamış Doktora Tezi, (State University of New York at Binghamton), Binghamton, New York, 2009.

, “Osmanlı Tarihyazımında 'Lale Devri': Eleștirel Bir Değerlendirme”, Tarih Toplum: Yeni Yaklaşımlar, 7, 2008, s. 129-144. 
I. EK: Vâkıa Takrîri Bin Yüz Kırk Üç'de Terkîb Olunmuşdur,

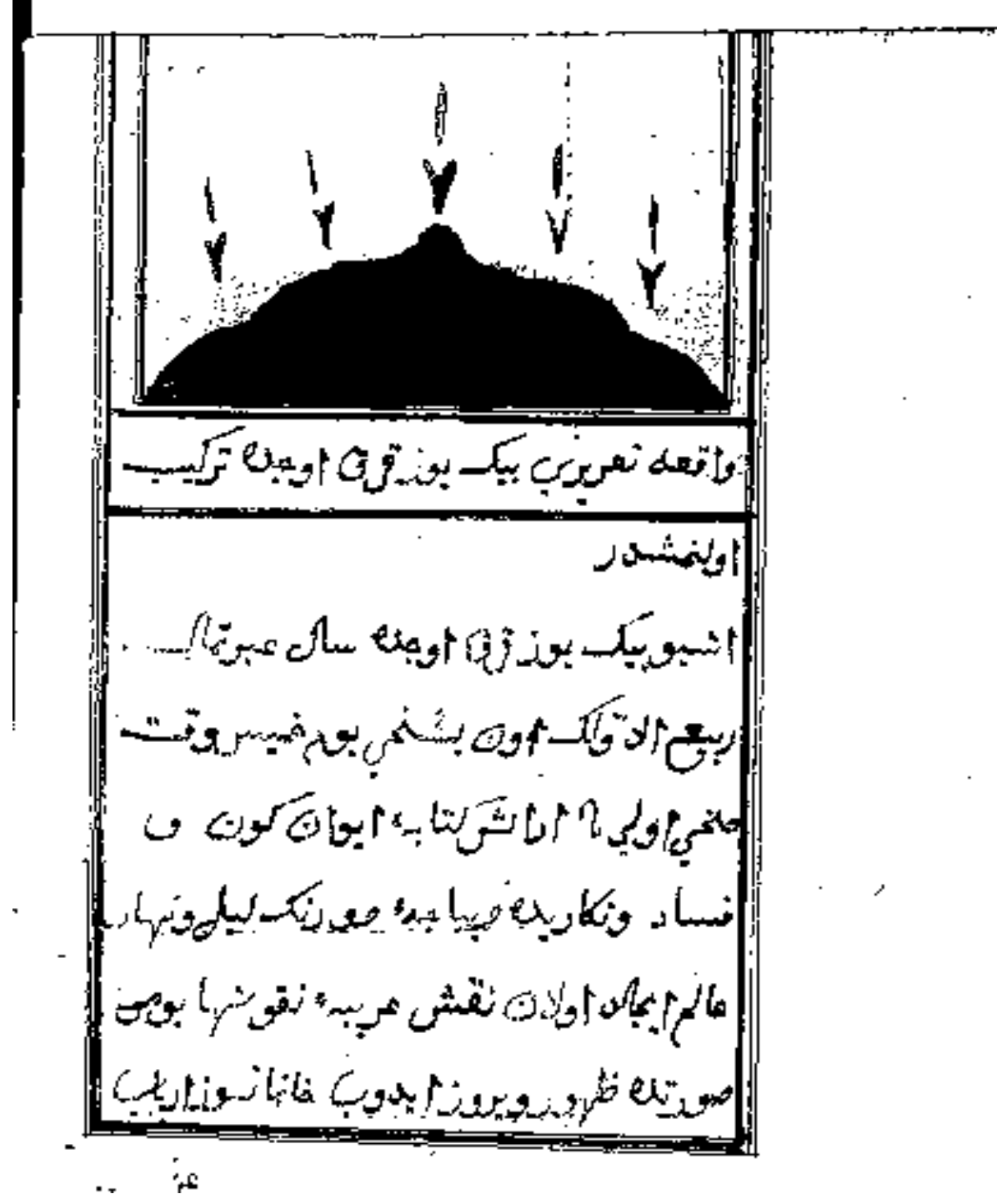

Metnin ilk sayfas 1 
II. EK: Vâkıa Takrîri Bin Yüz Kırk Üç'de Terkîb Olunmuşdur,

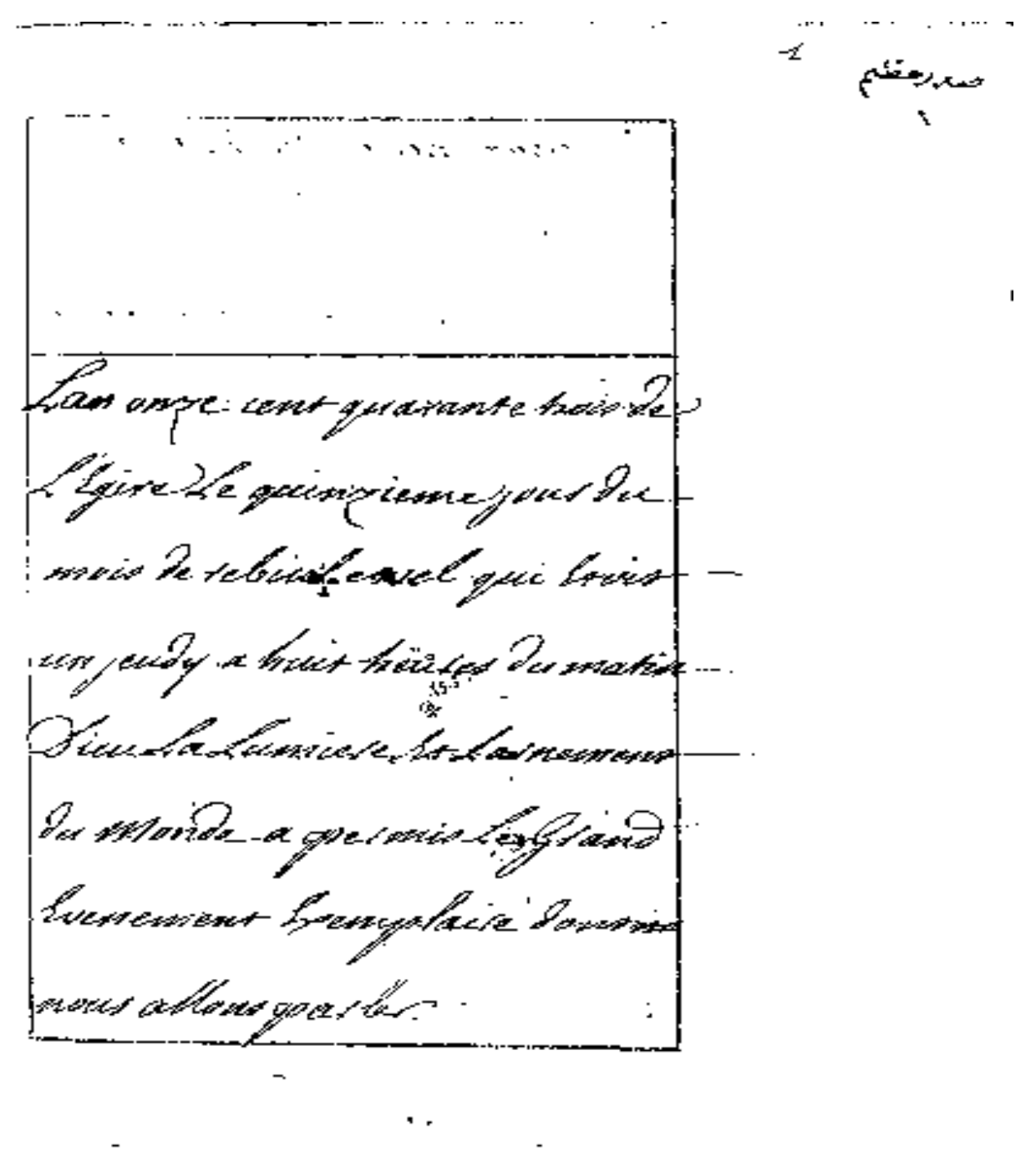

Fransızca Çevirinin İlk Sayfası 
Osmanlı İmparatorluğu'nda 1730 İsyanı Üzerine Yeni Bir Eser: Vâkı Takrîri Bin Yüz 187 Kırk Üç'de Terkîb Olunmuşdur

III. EK: Eserin Kapağ1

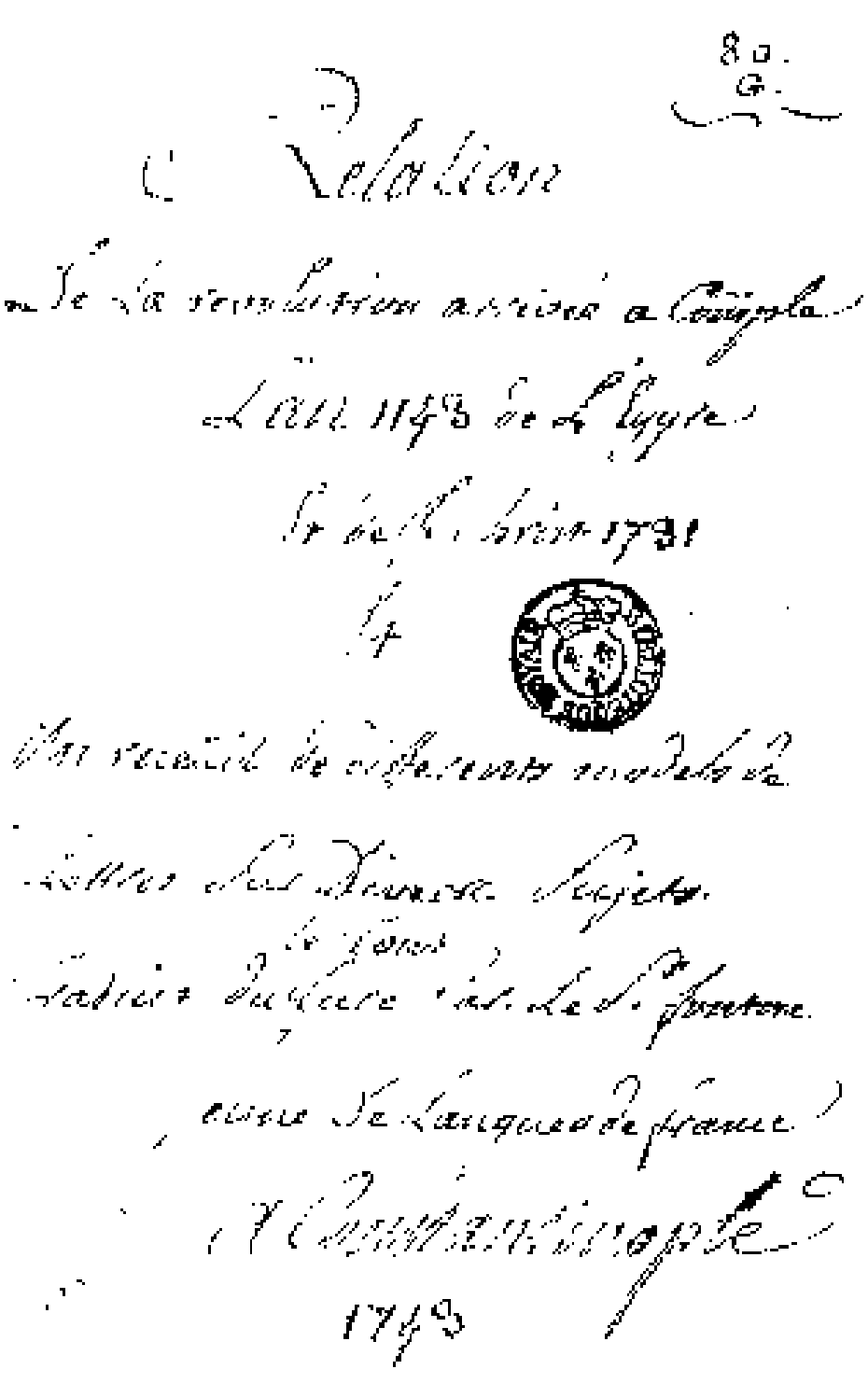

